\title{
A Review of Instant Messaging and Mobile Messaging Applications
}

\author{
Hsiu-Yuan Wang \\ Department of Hospitality Management, Chung Hua University, Hsiuchu, Taiwan, ROC \\ Email address: \\ hyjenniferwang@gmail.com
}

\section{To cite this article:}

Hsiu-Yuan Wang. A Review of Instant Messaging and Mobile Messaging Applications. International Journal of Economics, Finance and Management Sciences. Vol. 7, No. 1, 2019, pp. 13-15. doi: 10.11648/j.ijefm.20190701.13

Received: January 19, 2019; Accepted: March 7, 2019; Published: March 8, 2019

\begin{abstract}
Advanced mobile messaging applications are growing ever more popular as they begin to add different social networking features. Apart from free voice calls and instant text messaging with friends, mobile apps also offer idiosyncratic cartoon stickers that serve as emoticons and are designed to make communicating more fun. Thus, this article intends to review and to describe some features related to traditional instant messaging and advanced mobile messaging applications.
\end{abstract}

Keywords: Instant Messaging, Mobile Messaging, Line

\section{Introduction}

Today advanced mobile messaging applications (e.g., Line, WhatsApp, MessageMe, and Viber etc.) are growing ever more popular as they begin to add different social networking features. Basically, they are a form of rich emoticons that enhance the user's experience of messaging applications. Because communication on mobile devices has become more image-based-through the use of emoticons and stickers - companies have begun to create their own branded emoticons in order to engage potential customers in a new way.

\section{Traditional Instant Messaging}

Computer-based messaging could date back to the early computing era. In the early days of messaging, people primarily interacted via desktop computers. At that time, a wave of communication instant messaging/chat services emerged, including ICQ (I-seek-you), AIM (American Online Instant Messenger), Yahoo! Messenger, MSN Messenger, and so on, and gained huge popularity. According to Petronzio, we are easily able to understand the important advances that instant messaging applications have made over the past years [1].

In 1996, the Israeli company Mirabilis launched ICQ, a text-based messenger that was the first to really reach a widespread market of online users. In 1997, the American
Online Corporation released AIM, which also allowed users to send messages to each other. Yahoo launched Yahoo! Messenger in 1998 to attract a new generation of technology-savvy users. Subsequently, Microsoft released MSN Messenger in 1999 to enable users to exchange online messages. Founded in 2003, Skype allows Internet users to communicate with others by video, voice and instant messaging.

However, compared to video conferencing, the instant messaging aspect of Skype is not typically used by many people. In 2005, Google launched Google Talk. This service includes text-based messaging, voice calls and video conferencing. Additionally, Facebook released Facebook Chat in 2008, allowing people to connect with one friend or multiple people through the groups feature while logged into the social network. Over the past twenty years, instant messaging can therefore be seen as playing a large role in bringing people together.

\section{Mobile Messaging}

Most recently, as the Internet, smartphones and text messaging have spread to the general public, consumers have quickly gotten used to communicating with their peers or groups of people via text from a mobile device.

However, the traditional instant messaging services market, which peaked in 2012 and is now gradually shrinking, is being replaced by mobile messaging applications [2]. The reason for 
the rise to popularity of mobile messaging applications might be low- or no-cost alternatives to texting. Nowadays, mobile related messaging applications have taken center stage thanks to the sheer weight of their ever-expanding user bases.

There are many advanced messaging applications available in the global world. Based on Chan, we know that leading international messaging applications mainly include WhatsApp (United States), Viber (Cyprus), WeChat (China), Line (Japan), KakaoTalk (South Korea), Kik (Canada), Tango (United States), Nimbuzz (India), hike (India), MessageMe (United States), and so on [3].

However, human preferences for messaging applications differ by region. Line is one of the most popular messaging applications throughout Asia. The aim of Line is to be a super-popular and fun messaging application [4]. Line's stickers and fun characters, with their own online cartoons, all increase the attraction of Line to users. Therefore, Line's features have attracted the attention of brands, media owners, and potential customers.

\subsection{The Emergence of Line}

Line application was developed by NHN Japan, a subsidiary of the South Korean internet company Naver, to enable people to communicate easily with their family and friends. The key feature of the Line application is that users can text and call people from their smartphones.

As this function mainly involves chatting over the Internet rather than via the phone, users aren't charged for a phone call. Line's free messaging service proved a popular alternative to text-messaging and the application reached 100 million registered users within 18 months of its release [5]

\subsection{The Statistics of Line}

Early in October 2014, Line reported that it had reached 560 million registered users worldwide [6]. Furthermore, Line reported that its revenue grew by $70 \%$ to 28.1 billion Japanese yen in the first quarter of 2015. Recently, mobile messaging stickers have become increasingly popular. Sending a graphic is a faster way to express one's feeling, especially if one is typing in a character-alphabet language, like Chinese, Japanese, Korean, Vietnamese, etc.

Consumers really love stickers. According to Lomas, $40 \%$ of smartphone owners actively use stickers, and $20 \%$ of sticker users have purchased them at least once [7]. Bolluyt mentions that mobile messaging applications are growing increasingly important not only for consumers, but also for firms who want to connect with consumers [8]. Company-sponsored stickers are therefore a growing trend, and most of them are free to download. Line, which encourages companies to launch their own sticker packs, has been the leader in this space.

Based on Report from IPG media Lab, mobile messaging application stickers are social currency that could impress potential consumers and enhance brand awareness [9]. In the context of the Line application, many companies try to use stickers effectively to push and promote their brand image.
Combined with the explosion of smart phone adoption, the number of users of Line stickers is likely to grow by leaps and bounds in the near future.

\subsection{The Stickers of Mobile Messaging Applications}

Messaging application stickers convey messages that words cannot [10]. With social media shifting to mobile messaging, companies began to engage users through the use of stickers. The Disney Company jumped on the sticker craze by releasing its own free application [11]. Ford company recently launched a new branded sticker through mobile messaging applications [12]. Also, Coca-Cola (Japan) has utilized Line stickers as a freebie to promote its sports drink [13]. A chain restaurant made use of free company-branded Line stickers to delight customers [14]. Burger King provided customers with sticker to help attract their customers in conversation [15]. Due to consumers relying more and more on messaging applications to communicate with each other, company branded stickers may develop an important effect on advertisement that inserts the brand into the conversation [16].

\section{Conclusion}

Based on the above descriptions of the traditional instant messaging and mobile messaging development, we can roughly understand the major differences between the two, Nowadays, mobile internet could be viewed as a needs in people's everyday life. Traditional instant messaging applications have turned into mobile messaging/chatting styles, making peoples' chatting content more vivid and abundant.

Using mobile messaging applications can speed up communication and eliminate certain difficulties in expressing feelings in words, because it also allows users to express their emotions efficiently, clearly, and conveniently. Therefore, businesses and organizations could put effort into exploring some company related messaging stickers that may appeal to potential customers so as to impress them and indirectly increase their sales.

\section{References}

[1] M. Petronzio, "A brief history of instant messaging", available at: http://mashable.com/2012/10/25/instant-messaging-history/, 2012.

[2] Report from Budde Comm, "Global mobile media - messaging services and messaging apps insights", available at: http://www.budde.com.au/Research/Global-Mobile-Media-Me ssaging-Services-and-Messaging-Apps-Insights.html, 2015.

[3] S. E. Chan, "The 10 most popular mobile messaging apps in the world", available at:

http://readwrite.com/2014/03/06/10-biggest-popular-mobile-m essaging-apps-world-whatsapp, 2014.

[4] M. Sharma, "10 best messaging apps 2015", available at: http://www.compsmag.com/10-best-messaging-apps/, 2015. 
[5] Report from Statista, "Number of LINE app's registered users from December 2011 to October 2014", available at: http://www.statista.com/statistics/250926/number-of-registere d-line-app-users/, 2015a.

[6] Report from Statista, "Number of monthly active Line users worldwide as of 2nd quarter 2015", available at: http://www.statista.com/statistics/327292/number-of-monthlyactive-line-app-users/, 2015b.

[7] N. Lomas, "Global mobile Android/ios messaging app map dominated by WhatsApp - but BBM bags a foothold", available at:

http://techcrunch.com/2013/11/26/on-device-mobile-messagin g-apps/, 2013

[8] J. Bolluyt, "How chat apps are replacing social networks", available

http://www.cheatsheet.com/technology/how-chat-apps-are-rep lacing-social-networks.html/?a=viewall, 2015.

[9] Report from IPG media Lab, "Why messaging app stickers are serious business", available from https://www.ipglab.com/wp-content/uploads/2014/05/Stickers _Serious-Business_20140430.pdf, 2014.

[10] J. Russell, "Why is every messaging app under the sun trying to sell stickers to you?", available at: http://thenextweb.com/mobile/2013/10/03/why-is-every-mess aging-app-under-the-sun-trying-to-sell-stickers-to-you/, 2013.
[11] G. Yang, "Stickers \& emojis - Are they the real deal for advertisers?" available at: http://geekyyang.com/2015/08/07/stickers-emoji-are-they-thereal-deal-for-advertisers/, 2015.

[12] B. Jaekel, "Ford chases millennials on messaging apps via branded emojis", available at:

http://www.mobilemarketer.com/cms/news/messaging/21294. html, 2015.

[13] F. Matsumoto, H. Goto, and Y. Muramatsu, "Food and beverage makers turn to Line stickers", available at: http://asia.nikkei.com/Business/Trends/Food-and-beverage-ma kers-turn-to-Line-stickers, 2014.

[14] H. Chang, "Use Line stickers to shorten the distance between company and customers", available at: http://www.ieatpe.org.tw/magazine/ebook304/b4.pdf, 2016.

[15] K. Awuah, "Are iMessage stickers and apps the next big mobile marketing opportunity?" available at: https://www.impactbnd.com/blog/imessage-stickers-apps, 2016.

[16] K. Monllos, "Here's why your favorite brands are making their own emoticons", available at: http://www.adweek.com/news/advertising-branding/here-s-wh y-your-favorite-brands-are-making-their-own-emoticons-1633 25, 2015. 